\title{
Characteristics, management and outcomes of critically ill patients who are 80 years and older: a retrospective comparative cohort study
}

\author{
Hasan M Al-Dorzi ${ }^{1}$, Hani M Tamim²,3, Shihab Mundekkadan ${ }^{4}$, Muhammad R Sohail ${ }^{5}$ and Yaseen M Arabi $6^{*}$
}

\begin{abstract}
Background: Older age is associated with chronic illnesses and disability, which contribute to increased admission to the intensive care unit (ICU). Our primary objective was to compare the characteristics, ICU management and outcomes of critically ill patients $\geq 80$ year-old with those of younger patients.

Methods: This was a retrospective cohort study of patients admitted to a tertiary-care ICU from 1999 to 2011. The characteristics, ICU management and outcomes of patients $\geq 80$ year-old were compared with those 50-64.9 and 65-79.9 year-old. Multivariate analysis was performed to determine the adjusted risk of Do-Not-Resuscitate orders and hospital mortality in patients $\geq 80$ year-old compared with the younger groups.

Results: During the study period, patients aged $\geq 80$ years $(N=748)$ represented $7.9 \%$ of all ICU admissions and $12.8 \%$ of patients aged $\geq 50$ years. Chronic cardiac (32.2\%) and respiratory (21.8\%) diseases were more prevalent in them than the younger groups $(p<0.0001)$. The most common reasons for their ICU admission were cardiovascular (30.9\%) and respiratory (40.4\%) conditions. Sepsis was commonly present in them on admission (32.9\%). Mechanical ventilation and renal replacement therapy were commonly provided ( $76.9 \%$ and $16.0 \%$, respectively). During ICU stay, Do-Not-Resuscitate orders were more frequently written for patients aged $\geq 80$ years (35.0\%) compared with $21.9 \%$ for $50-64.9$ year-old group, $p<0.0001$, and $25.4 \%$ for the $60-79.9$ year-old group, $p<0.0001$. On multivariate analysis, patients aged $\geq 80$ years were more likely to receive these order compared with the 50-64.9 year-old patients (adjusted OR, 1.83; 95\% Cl, 1.45-2.31) and the 65-80 year-old patients (adjusted OR, 1.64; 95\% Cl, 1.32-2.04). The hospital mortality increased gradually with age and was highest (54.6\%) in patients $\geq 80$ year-old ( $p<0.0001)$. Patients $\geq 80$ year-old had higher risk of hospital mortality compared with patients aged 50-64.9 years (adjusted OR, $2.16 ; 95 \% \mathrm{Cl}, 1.73-2.69$ ) and with those aged $65-79.9$ years (adjusted $\mathrm{OR}, 1.51 ; 95 \% \mathrm{Cl}, 1.23-1.86$ ).
\end{abstract}

Conclusions: Patients $\geq 80$ year-old represented a significant proportion of ICU admissions. Although they received life sustaining measures similar to younger groups, they had higher adjusted mortality risk compared with the younger groups.

Keywords: Aged 80 and over, Critical illness, Health outcome, Mortality

\section{Background}

Old age is associated with chronic medical diseases and functional impairment, which may lead to increased incidence and severity of acute critical illnesses and to admission to the intensive care unit (ICU). For severe sepsis, the incidence generally increases with age during

\footnotetext{
* Correspondence: yaseenarabi@yahoo.com

${ }^{6}$ College of Medicine, King Saud bin Abdulaziz University for Health Sciences, PO Box 22490, Mail code 1425, Riyadh 11426, Kingdom of Saudi Arabia Full list of author information is available at the end of the article
}

adulthood [1]. Incidence of hospitalization secondary to community-acquired pneumonia doubles in patients aged $>60$ years [2]. A study from the United Kingdom found that the ratio of ICU admissions to local population in people $\geq 60$ years rose linearly by 2.62 admissions per 10,000 population per year over a six consecutive year-period with the increase being highest in patients $\geq 80$ years [3].

Rationing health care based upon age has been reported. In a systematic review, Sinuf et al. studied rationing of 
ICU resources and found that age and severity of illness were most strongly associated with a refusal to admit to the ICU [4]. A recent prospective cohort study of patients $>85$ year-old presenting to the emergency departments of 15 Parisian hospitals found significant variability in ICU admission even after adjustment for patient characteristics [4]. This was likely related to the belief that older age was associated with poor outcomes after ICU admission [5]. This issue has been investigated in multiple studies mostly from Western countries [6-8]. However, it is also believed that age explains only a small part of the outcomes of critical illness and that prior functional status, co-morbidities and the level of therapeutic support are important factors [9].

Knowing the outcomes and prognosis determinants of patients aged $\geq 80$ years who are admitted to the ICU is important for clarification of perceptions of intensive care providers and possibly for proper allocation of resources. The objectives of this study were to describe the characteristics, management and outcomes of critically ill patients $\geq 80$ year-old and to determine if age $\geq 80$ years was an independent predictor of ICU management and of hospital mortality in a tertiary-care center in Saudi Arabia.

\section{Methods}

\section{Patients and setting}

This was a retrospective analysis of a cohort of adult patients admitted between January 1, 1999 and December 31, 2011 to the ICU of King Abdulaziz Medical City, a 900-bed tertiary-care teaching hospital in Riyadh, Saudi Arabia that had been accredited by the Joint Commission International. The ICU was a 21-bed medical-surgical closed unit and was staffed by board-certified critical care physicians on a 24 hours per days, 7 days a week basis [10] with residents from different specialties rotating periodically. In this study, we compared patients $\geq 80$ year-old with those 50-64.9 and 65-79.9 year-old because the younger patients $(<50$ year-old) were thought to have completely different comorbid conditions, reasons for ICU admission and end-of-life care. For patients who had multiple ICU admissions in the same hospitalization, we included only the first ICU admission. The Institutional Review Board of King Saud bin Abdulaziz University for Health Sciences, Riyadh, Saudi Arabia approved this study, granted waiver of consent and allowed the review of the patients' medical records.

\section{Collected data}

Our Intensive Care Department had a comprehensive database in which trained coordinators prospectively collected demographic and clinical data and followed patients for predefined outcomes. The following data were extracted from the database: age, gender, body mass index, functional status before hospitalization based on the modified Rankin Scale [11], Acute Physiology and Chronic Health Evaluation (APACHE) II score [12], the presence of chronic health illnesses as defined by APACHE II system, the main reason for ICU admission (as per APACHE II definitions), presence of sepsis on admission, diagnosis of the following on ICU admission: myocardial ischemia such as acute coronary syndrome and acute myocardial infarction, community- or hospital-acquired pneumonia and new stroke, admission Glasgow Coma Scale score and admission platelet count, creatinine, lactate, bilirubin and International Normalized Ratio (INR).

We also noted the following ICU management aspects: use of vasopressors within the first 24 hours after ICU admission, requirement for mechanical ventilation, renal replacement therapy and tracheostomy during ICU stay, performance of cardiopulmonary resuscitation for cardiac arrest while in the ICU and the practice of Do-NotResuscitate orders. During the study period, advanced directives were not practiced in Saudi Arabia. However, our hospital had a policy in which a Do-Not-Resuscitate order can be written if three qualified physicians agreed that a patient would not benefit from cardiopulmonary resuscitation in case of cardiac arrest because of he/she was terminally ill or had a severe illness with high predicted mortality, especially if significant functional disability and/or dementia preexisted. This medical decision would be then explained to the patient or surrogate decision maker who generally had to agree before its implementation. His or her signature was not required. Do-NotResuscitate orders generally precluded intubation but not the use of noninvasive ventilation.

In this study, hospital mortality was the primary outcome. Other outcomes included ICU and post-ICU discharge mortality, length of stay in the ICU and hospital and duration of mechanical ventilation. We also calculated the predicted mortality based on the Mortality Probability Model (MPM) II at 0 and 24 hours [13] and on APACHE II score for the three age groups.

\section{Statistical analysis}

Statistical analysis was done using Statistical Analysis System (SAS, version 9.0; SAS Institute, Cary, NC). Continuous variables were reported as means with standard deviations and if clinically relevant as medians with the first and third quartiles. Categorical variables were presented as frequencies with percentages. The standardized mortality ratio for APACHE II was calculated for each group by dividing the actual by predicted hospital mortality and reported with its $95 \%$ confidence intervals (CI) [14]. The Chi-squared test was used to assess the differences between categorical variables and the Student's t-test to assess the differences between continuous variables. Multivariate analysis was performed to evaluate older patients' adjusted risk of hospital mortality, having a 
Do-Not-Resuscitate order during ICU stay and need for renal replacement therapy. The association between hospital mortality and age was also evaluated in patients admitted to the ICU because of cardiovascular, respiratory, neurological, other medical, trauma-related and postoperative reasons and in patients with the diagnosis of myocardial ischemia, community- or hospital-acquired pneumonia and new stroke on ICU admission. Multivariate analysis was also performed to determine the predictors of hospital mortality in patients $\geq 80$ year-old. The independent variables entered in these analyses were gender, nonage-related APACHE II score, the main reason for admission, chronic illnesses, functional status before hospitalization (moderately severe or severe disability versus more active status), mechanical ventilation, length of ICU stay, creatinine and INR. The results were presented as adjusted odds ratio (aOR) with 95\% CIs. A P-value $<0.05$ was considered statistically significant in all analyses.

\section{Results}

\section{Characteristics of patients}

During the 13 year study period, 9493 patients were admitted to the ICU. The patients aged $\geq 80$ years $(\mathrm{N}=748)$ represented $7.9 \%$ of them and $12.8 \%$ of the 5832 patients who were 50 years and older. Their mean age was $85.1 \pm 4.9$ years (Q1-Q3: $81-88$ years). Figure $1 \mathrm{~A}$ describes the age distribution of the cohort according to gender. Men aged $\geq 80$ years accounted for $8.1 \%$ of admitted men and women aged $\geq 80$ years $7.6 \%$ of admitted women. Figure $1 \mathrm{~B}$ describes the percentages of patients aged $\geq 80$ years admitted from 1999 to 2011 and shows random variation between years. Additionally, Table 1 describes the characteristic of the three age groups. The oldest ( $\geq 80$ year-old) patients were predominantly males (64.2\%) with APACHE II score = $27.2 \pm 8.2$. Chronic cardiac (32.2\%) and respiratory (21.8\%) diseases were more prevalent in them than in the younger groups $(\mathrm{p}<0.0001)$. More patients aged $\geq 80$ years had moderate or severe physical disability before hospitalization as assessed by the modified Rankin Scale. Disorders of the respiratory (40.4\%) and cardiovascular (30.9\%) systems were their most common reasons for admission to the ICU. Sepsis was present on admission in $32.9 \%$, the highest among the groups $(\mathrm{p}<0.0001)$. Myocardial ischemia, community-acquired pneumonia and new stroke on admission were also more prevalent.

\section{Intensive care unit management}

Table 2 describes certain aspects of ICU management for the three age groups. Use of vasopressors was similar in patients aged $\geq 80$ years compared with the two younger groups. Patients aged $\geq 80$ years had the highest rate of mechanical ventilation (76.9\%) and the lowest rate of renal replacement therapy (16.0\%). Multivariate analysis showed that the OR for providing renal replacement therapy was not different in patients aged $>80$ years compared to 50-65 year-old patients (aOR, 0.824; 95\% CI, 0.6131.107 ) and 60-79.9 year old patients (aOR, 0.87; 95\% CI, $0.65-1.15)$. Tracheostomy was performed more frequently in patients aged $\geq 80$ years even though there was no difference in the duration of mechanical ventilation among the three groups.

Figure 2 describes the percentages of patients in the different age groups who had Do-Not-Resuscitate orders during their ICU stay. Do-Not-Resuscitate orders were more frequently written for patients aged $\geq 80$ years (35.0\%) compared with $21.9 \%$ for 50-64.9 year-old group, $\mathrm{p}<0.0001$, and $25.4 \%$ for the 60-79.9 year-old group, $\mathrm{p}<0.0001$ (Table 2). In addition, Do-Not-Resuscitate orders were written earlier (median day after ICU admission, 3; Q1-Q3: 1-8 days) than for patients $<80$ year-old (median, 5; Q1-Q3: 1-10 days for the 50-64.9 year-old and median, 5; Q1-Q3, 1-11 days for the 65-79.9 yearold). After controlling for other factors and compared with patients 50-64.9 years, the practice of Do-NotResuscitate orders was similar in patients who were 65-80 year-old (aOR, 1.16; 95\% CI, 0.98-1.37) but higher for patients aged $\geq 80$ years (aOR, 1.83; 95\% CI, 1.45-2.31). Additionally, patients aged $\geq 80$ years were more likely to have Do-Not-Resuscitate order compared with patients who were 65-80 year-old (aOR, 1.64; 95\% CI, 1.32-2.04).

\section{Outcomes}

Table 3 describes the outcomes of the patient groups. The lengths of stay in the ICU and hospital were similar in the three groups. Although there was no difference in ICU mortality between the three age groups, hospital mortality increased gradually with age and was highest (54.6\%) in patients $\geq 80$ years old $(\mathrm{p}<0.0001)$. Moreover, the hospital mortality rates for patients who had Do-Not-Resuscitate order while in the ICU were $92.6 \%$ for the younger group, $89.7 \%$ for patients aged $65-79.9$ years and $85.1 \%$ for the very elderly. The mortality rates of patients who had cardiopulmonary resuscitation for cardiac arrest while in the ICU were $82.7 \%$ for the younger group, $79.5 \%$ for patients aged $65-79.9$ years and $80.6 \%$ for the very elderly.

Figure 3 describes the hospital mortality of the three age groups stratified by the reason of admission and generally shows that the mortality rates increased with age. This was not observed in patients admitted to the ICU because of hospital acquired pneumonia and neurologic disease. After adjusting for imbalances in the baseline characteristics, patients $\geq 80$ year-old had higher risk of hospital mortality compared to patients aged 50-64.9 years (aOR, 2.16; 95\% CI, 1.73-2.69) and those aged 65-79.9 (aOR, 1.51; 95\% CI, 1.23-1.86). This increased risk was not observed in patients with ICU admission because of neurologic disorders, new stroke or hospital-acquired pneumonia (Figure 3). 


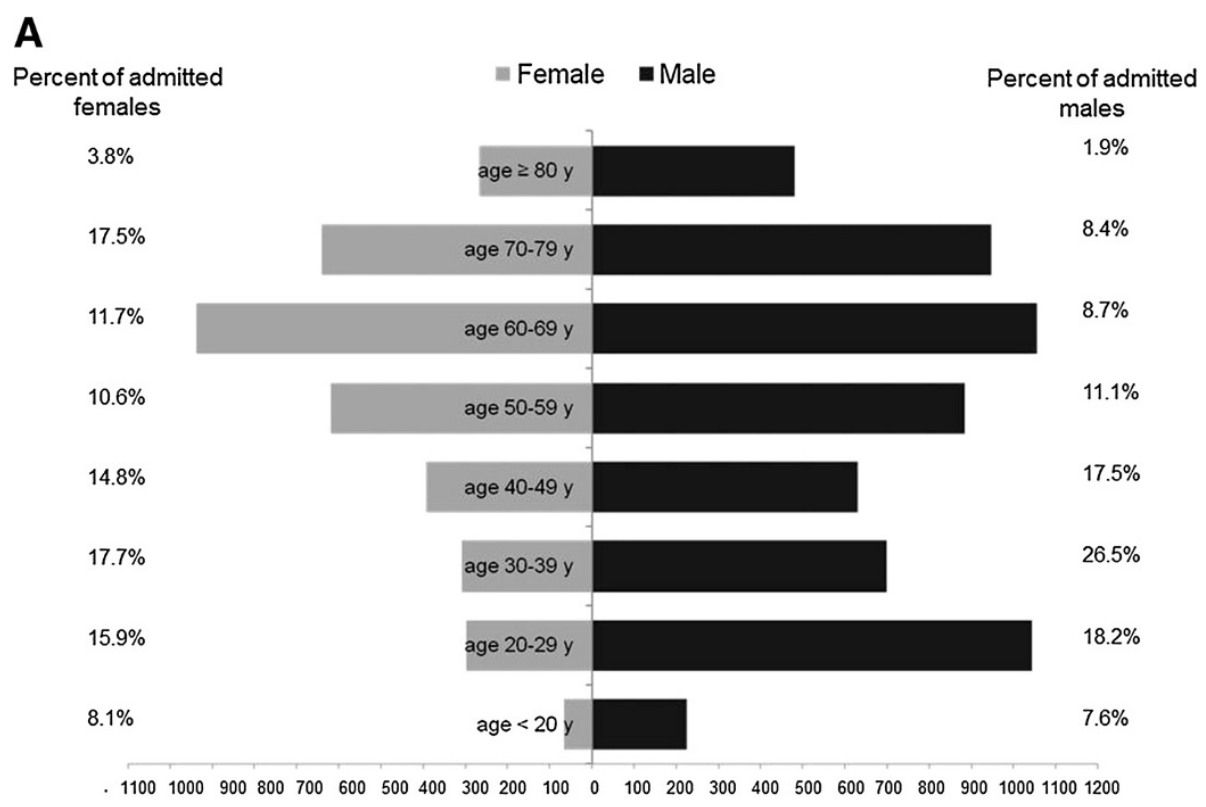

Frequency of patients in the cohort stratified by gender and age group

B

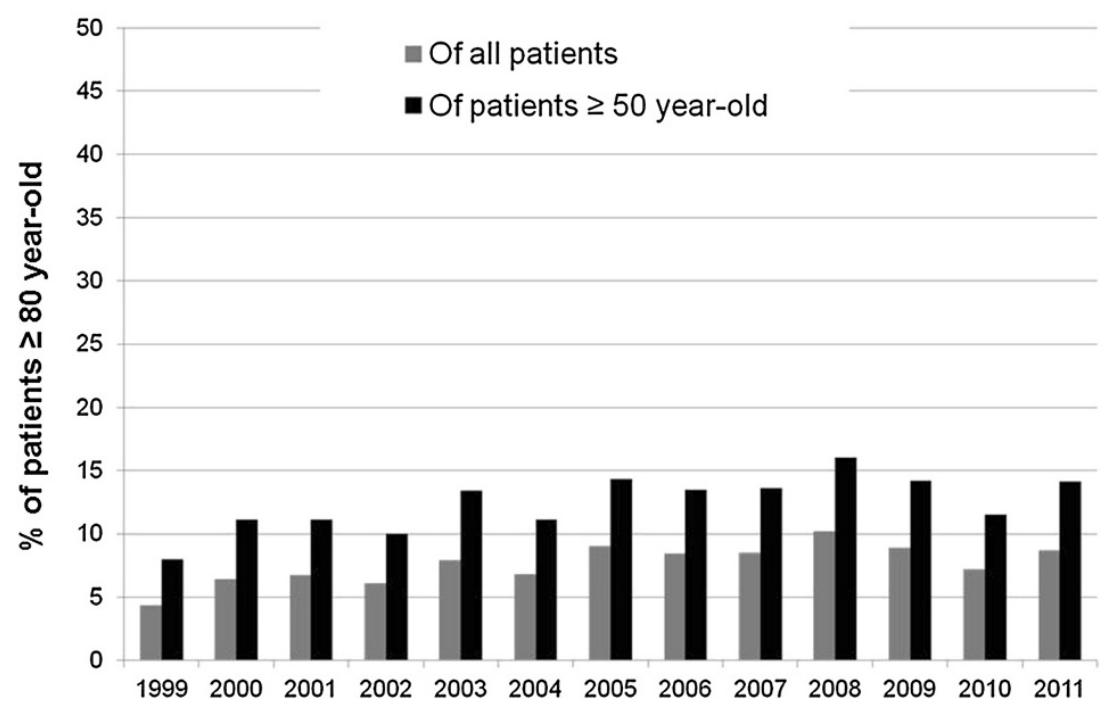

Figure 1 Cohort description. Panel A: Age distribution by decades of the cohort according to gender. Panel B: Percentages of patients aged $\geq 80$ years old of all patients and of patients $\geq 50$ years old admitted to the intensive care unit per admission year.

Predictors of hospital mortality in patients who were 80 years or older were invasive mechanical ventilation (OR, 3.10; 95\% CI, 1.96-4.90), chronic renal disease (OR, 1.75; 95\% CI, 1.05-2.90), non-age APACHE II score (OR, 1.07; 95\% CI, 1.04-1.10) and length of ICU stay (OR, 1.04 per one day increment; $95 \% \mathrm{CI}, 1.02-1.07)$.

\section{Discussion}

The main findings of this study were the following: patients aged $\geq 80$ years represented a significant portion of patients admitted to the ICU; had significant comorbid conditions; were admitted mainly because of acute dysfunction of the cardiac and respiratory systems; and compared with the younger groups, received similar life sustaining treatments but were more likely to have Do-Not-Resuscitate orders and to die in the hospital than the younger groups.

The age structure of the world population has shifted and will continue to do so with the proportion of old people increasing in both developed and developing countries [15]. In parallel with this shift, more old patients are admitted to ICU. In Australia and New Zealand, the proportion of patients aged $>80$ years was $13 \%$ of the 
Table 1 Patient characteristics

\begin{tabular}{|c|c|c|c|c|c|c|}
\hline & $\begin{array}{l}50-64.9 \text { yr-old } \\
\mathrm{N}=2467\end{array}$ & $\begin{array}{l}65-79.9 \text { yr-old } \\
\mathrm{N}=2617\end{array}$ & $\begin{array}{l}\geq 80 \text { yr-old } \\
N=748\end{array}$ & P-value* & P-value** & P-value*** \\
\hline Age (years), mean $\pm S D$ & $57.6 \pm 4.3$ & $71.1 \pm 4.1$ & $85.1 \pm 4.9$ & $<0.0001$ & $<0.0001$ & $<0.0001$ \\
\hline Male gender, N (\%) & $1377(55.8)$ & $1507(57.6)$ & $480(64.2)$ & 0.20 & $<0.0001$ & 0.0012 \\
\hline $\mathrm{APACHE} \|$, mean $\pm \mathrm{SD}$ & $23.3 \pm 9.1$ & $26.5 \pm 8.7$ & $27.1 \pm 8.0$ & $<0.0001$ & $<0.0001$ & 0.11 \\
\hline Non-age APACHE II, mean \pm SD & $20.5 \pm 9.0$ & $21.2 \pm 8.7$ & $21.1 \pm 8.0$ & 0.02 & 0.14 & 0.75 \\
\hline Body mass index $\left(\mathrm{Kg} / \mathrm{m}^{2}\right)$, mean $\pm \mathrm{SD}$ & $29.1 \pm 7.7$ & $28.4 \pm 8.0$ & $27.1 \pm 7.9$ & 0.02 & $<0.0001$ & 0.001 \\
\hline \multicolumn{7}{|l|}{ Functional status ${ }^{\ddagger}$ before admission, N (\%) } \\
\hline No significant disability & $801(32.6)$ & $395(15.3)$ & $61(8.2)$ & $<0.0001$ & $<0.0001$ & $<0.0001$ \\
\hline Slight disability & $573(23.4)$ & $506(19.5)$ & $73(9.8)$ & 0.0006 & $<0.0001$ & $<0.0001$ \\
\hline Moderate disability & $429(17.6)$ & $691(26.6)$ & $691(20.0)$ & $<0.0001$ & 0.13 & 0.0003 \\
\hline Moderately severe disability & $172(7.0)$ & $467(18.0)$ & $262(35.2)$ & $<0.0001$ & $<0.0001$ & $<0.0001$ \\
\hline Severe disability & $91(3.7)$ & $233(9.0)$ & $117(15.7)$ & $<0.0001$ & $<0.0001$ & $<0.0001$ \\
\hline \multicolumn{7}{|l|}{ Chronic illnesses, N (\%) } \\
\hline Cardiac & $413(16.9)$ & $644(24.8)$ & $240(32.2)$ & $<0.0001$ & $<0.0001$ & $<0.0001$ \\
\hline Respiratory & $328(13.4)$ & $475(18.4)$ & $162(21.8)$ & $<0.0001$ & $<0.0001$ & 0.04 \\
\hline Renal & $379(15.5)$ & $476(18.4)$ & $120(16.2)$ & 0.007 & 0.68 & 0.16 \\
\hline Hepatic & $511(20.9)$ & $354(13.7)$ & $46(6.2)$ & $<0.0001$ & $<0.0001$ & $<0.0001$ \\
\hline Immunocompromised & $349(14.3)$ & $303(11.7)$ & $56(7.5)$ & 0.007 & $<0.0001$ & 0.001 \\
\hline \multicolumn{7}{|l|}{ Main reason for ICU admission, N (\%) } \\
\hline Cardiovascular & $452(18.3)$ & $655(25)$ & $231(30.9)$ & $<0.0001$ & $<0.0001$ & 0.0001 \\
\hline Respiratory & $862(34.9)$ & $1016(38.8)$ & $302(40.4)$ & $<0.0001$ & $<0.0001$ & 0.0001 \\
\hline Neurological & $175(7.1)$ & $181(6.9)$ & $60(8.0)$ & $<0.0001$ & $<0.0001$ & 0.0001 \\
\hline Other medical & $198(8.0)$ & $159(6)$ & $34(4.6)$ & $<0.0001$ & $<0.0001$ & 0.0001 \\
\hline Non-operative trauma & $84(3.4)$ & $47(1.8)$ & $7(0.9)$ & $<0.0001$ & $<0.0001$ & 0.0001 \\
\hline Post operative & $696(28.2)$ & $559(21.4)$ & $114(15.3)$ & $<0.0001$ & $<0.0001$ & 0.0001 \\
\hline Sepsis on admission, N (\%) & $723(29.3)$ & $723(29.3)$ & $838(32)$ & 0.04 & 0.06 & 0.65 \\
\hline Myocardial ischemia on admission, N (\%) & $227(9.2)$ & $367(14.0)$ & $151(20.2)$ & $<0.0001$ & $<0.0001$ & $<0.0001$ \\
\hline Community-acquired pneumonia on admission, N (\%) & $207(8.4)$ & $348(13.3)$ & $99(13.2)$ & $<0.0001$ & $<0.0001$ & 0.96 \\
\hline Hospital-acquired pneumonia on admission, N (\%) & $83(3.4)$ & $95(3.6)$ & $33(4.4)$ & 0.61 & 0.18 & 0.32 \\
\hline New stroke on admission, $\mathrm{N}(\%)$ & $227(9.2)$ & $478(18.2)$ & $175(23.4)$ & $<0.0001$ & $<0.0001$ & 0.002 \\
\hline Admission GCS score, mean \pm SD & $10.5 \pm 4.5$ & $10.0 \pm 4.5$ & $9.2 \pm 4.3$ & 0.0002 & $<0.0001$ & $<0.0001$ \\
\hline Platelet count $/ \mu \mathrm{L}$, mean $\pm \mathrm{SD}$ & $212 \pm 153$ & $227 \pm 153$ & $243 \pm 131$ & 0.004 & $<0.0001$ & 0.015 \\
\hline Lactate" (mmol/L), mean \pm SD & $3.8 \pm 4.0$ & $3.7 \pm 4.0$ & $3.5 \pm 3.8$ & 0.66 & 0.12 & 0.20 \\
\hline Creatinine" $(\mu \mathrm{mol} / \mathrm{L})$, mean $\pm \mathrm{SD}$ & $183 \pm 175$ & $190 \pm 161$ & $169 \pm 130$ & 0.18 & 0.052 & 0.005 \\
\hline Bilirubin* $(\mu$ mol/L), mean $\pm S D$ & $72 \pm 138$ & $44 \pm 90$ & $27 \pm 61$ & $<0.0001$ & $<0.0001$ & 0.0001 \\
\hline INR, mean $\pm S D$ & $1.7 \pm 1.1$ & $1.7 \pm 1.0$ & $1.7 \pm 1.1$ & 0.66 & 0.6 & 0.88 \\
\hline
\end{tabular}

APACHE, Acute Physiology and Chronic Health Evaluation; ICU, intensive care unit; INR, International Normalized Ratio; SD, standard deviation;

*P-value between patients aged 50-64.9 and those 65-79.9 years.

** P-value between patients aged $50-64.9$ and those $\geq 80$ years.

***P-value between patients aged $65-79.9$ and those $\geq 80$ years.

łbased on the modified Rankin Scale.

१To convert creatinine to $\mathrm{mg} / \mathrm{dL}$ divide by 88.4 , bilirubin to $\mathrm{mg} / \mathrm{dL}$ divide by 17.1 , lactate to $\mathrm{mg} / \mathrm{dL}$ divide by 0.111 .

adult ICU population and increased by $5.6 \%$ between 2000 and 2005 [16]. In Denmark, a study of 49,938 ICU admissions found that the proportion of patients aged $\geq$ 80 years increased from $11.7 \%$ of all ICU patients in 2005 to $13.8 \%$ in 2011 [17]. In the current study, patients aged $\geq$
80 years constituted $7.9 \%$ of all patients admitted to the ICU between 1999 and 2011 and $12.8 \%$ of patients $\geq$ 50 year-old, with the proportion of admissions generally showing random variation from year to year. These findings are different than other studies [16,17] likely because 
Table 2 Intensive care unit management

\begin{tabular}{lllllll}
\hline & $\begin{array}{l}\mathbf{5 0 - 6 4 . 9} \text { yr-old } \\
\mathbf{N = 2 4 6 7}\end{array}$ & $\begin{array}{l}\mathbf{6 5 - 7 9 . 9} \text { yr-old } \\
\mathbf{N = \mathbf { 2 6 1 7 }}\end{array}$ & $\begin{array}{l}\mathbf{2} \mathbf{8 0} \text { yr-old } \\
\mathbf{N = 7 4 8}\end{array}$ & P-value* & P-value** & P-value*** \\
\hline Use of vasopressors in the first ICU day, N (\%) & $975(40.2)$ & $1121(43.6)$ & $317(43.0)$ & 0.01 & 0.17 & 0.74 \\
Requirement of mechanical ventilation, N (\%) & $1735(70.4)$ & $1863(71.2)$ & $575(76.9)$ & 0.50 & 0.0005 & 0.002 \\
Renal replacement therapy, N (\%) & $536(21.7)$ & $554(21.2)$ & $120(16.0)$ & 0.63 & 0.0007 & 0.002 \\
Tracheostomy, N (\%) & $318(12.9)$ & $387(14.8)$ & $142(19.0)$ & 0.05 & $<0.0001$ & 0.005 \\
Cardiopulmonary resuscitation in the ICU, N (\%) & $150(6.1)$ & $195(7.4)$ & $72(9.6)$ & 0.052 & 0.0008 & 0.052 \\
Do-Not-Resuscitate order in the ICU, N (\%) & $542(21.9)$ & $663(25.4)$ & $262(35.0)$ & 0.005 & $<0.0001$ & $<0.0001$ \\
\hline
\end{tabular}

ICU, intensive care unit.

*P-value between patients aged $50-64.9$ and those 65-79.9 years.

** P-value between patients aged $50-64.9$ and those $\geq 80$ years.

***P-value between patients aged $65-79.9$ and those $\geq 80$ years.

the Saudi population is much younger than those of developed countries. In 2011, people aged $\geq 80$ years represented $0.6 \%$ of the population compared with $3.8 \%$ in Australia, 4.2\% in Denmark and 3.8\% in the United States [18].

Physicians frequently consider old age when deciding on the provision of life-sustaining measures. An observational simulation study found that 86,78 and $62 \%$ of participating physicians (predominantly males without religious beliefs; median ICU experience $=9$ years) felt that noninvasive mechanical ventilation, invasive mechanical ventilation or renal replacement therapy was warranted, respectively for patients aged $\geq 80$ years [19]. On multivariate analysis, age $<$ 85 years, self-sufficiency and bed availability were associated with ICU admission [19]. In a systematic review of 10 observational studies of seriously ill patients considered for ICU admission during periods of reduced bed availability, Sinuff et al. found that age and severity of illness were most strongly associated with a refusal to admit to the ICU [4]. A recent prospective study of patients $>85$ years presenting to the emergency departments of 15 Parisian hospitals found significant variability in ICU admission even after adjustment for patients' characteristics [5]. The geographic variation in ICU use for patients $\geq 85$ years old was also seen in another study where it was less common in England (1.3\%) than the United States (11.0\%) [20]. In the current study, we have observed that patients aged $\geq 80$ years were frequently provided with life support measures, such as mechanical ventilation and renal replacement therapy, like younger patients. However, age $\geq 80$ years was found to be an independent risk factor for the practice of Do-Not-Resuscitate orders after controlling for co-morbid conditions.

Low physiological reserve and comorbidities often place very old people in a situation of greater complexity, which may impact outcome. However, it is thought that they have lived to that age because they are resilient to acute illnesses. Studies generally show higher critical illnessassociated mortality in the old and very old patients. A

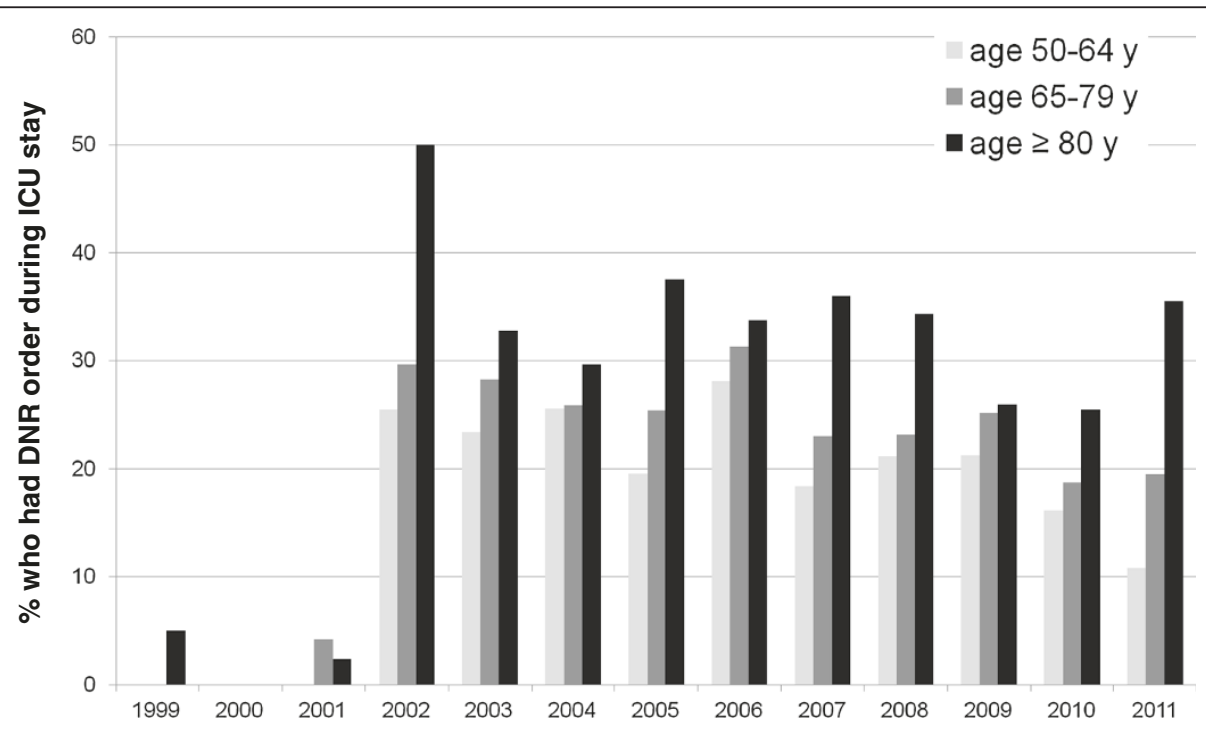

Figure 2 Percentage of patients in the three age groups (50-64.9, 65-79.9 and $\geq 80$ year-old) who had Do-Not-Resuscitate order during the stay in the intensive care unit per admission year. 
Table 3 Outcomes of patients in the three age groups

\begin{tabular}{|c|c|c|c|c|c|c|}
\hline & $\begin{array}{l}50-64.9 \text { yr-old } \\
\mathrm{N}=2467\end{array}$ & $\begin{array}{l}65-79.9 \text { yr-old } \\
N=2617\end{array}$ & $\begin{array}{l}\geq 80 \text { yr-old } \\
N=748\end{array}$ & P-value* & P-value** & P-value $* * * *$ \\
\hline $\begin{array}{l}\text { Duration of mechanical ventilation (days), } \\
\text { mean } \pm \text { SD }\end{array}$ & $6.4 \pm 10.5$ & $6.4 \pm 10.4$ & $6.9 \pm 8.8$ & 0.97 & 0.85 & 0.87 \\
\hline ICU LOS (days), mean \pm SD & $7.8 \pm 11.4$ & $7.8 \pm 11.1$ & $7.4 \pm 8.7$ & 0.98 & 0.42 & 0.33 \\
\hline Hospital LOS (days), mean \pm SD & $44.2 \pm 97.6$ & $45.1 \pm 136.8$ & $48.7 \pm 189.1$ & 0.78 & 0.54 & 0.63 \\
\hline ICU mortality, N (\%) & $637(25.8)$ & $723(27.6)$ & $217(29.0)$ & 0.15 & 0.08 & 0.46 \\
\hline Post-ICU mortality of all ICU survivors, N (\%) & $340(18.6)$ & $486(25.7)$ & $193(36.4)$ & $<0.0001$ & $<0.0001$ & $<0.0001$ \\
\hline $\begin{array}{l}\text { Post ICU mortality of patients without } \\
\text { Do-Not-Resuscitate orders, } N(\%)\end{array}$ & $270(15.7)$ & $386(22.4)$ & $129(30.1)$ & $<0.0001$ & $<0.0001$ & 0.0007 \\
\hline $\begin{array}{l}\text { Post ICU mortality of patients with } \\
\text { Do-Not-Resuscitate orders, } \mathrm{N}(\%)\end{array}$ & $70(63.6)$ & $100(59.5)$ & $64(62.1)$ & 0.49 & 0.82 & 0.67 \\
\hline 28-day mortality ${ }^{\#}, \mathrm{~N}(\%)$ & $719(29.1)$ & $838(32.0)$ & $275(36.8)$ & 0.03 & $<0.0001$ & 0.02 \\
\hline Hospital mortality, N (\%) & $977(39.6)$ & $1208(46.2)$ & $410(54.8)$ & $<0.0001$ & $<0.0001$ & $<0.0001$ \\
\hline \multicolumn{7}{|l|}{ Predicted mortality, mean $\% \pm S D$} \\
\hline APACHE $\|$ & $44.9 \pm 28.0$ & $53.8 \pm 27.0$ & $56.7 \pm 25.7$ & $<0.0001$ & $<0.0001$ & 0.02 \\
\hline $\mathrm{MPM}_{0} \|$ & $38.6 \pm 30.1$ & $46.7 \pm 30.9$ & $55.8 \pm 29.0$ & $<0.0001$ & $<0.0001$ & $<0.0001$ \\
\hline $\mathrm{MPM}_{24} \|$ & $41.2 \pm 31.3$ & $48.4 \pm 31.5$ & $54.4 \pm 30.0$ & $<0.0001$ & $<0.0001$ & $<0.0001$ \\
\hline Standardized mortality rate, (95\% confidence interval) & $0.88(0.84-0.92)$ & $0.86(0.82-0.89)$ & $0.97(0.90-1.03)$ & & & \\
\hline
\end{tabular}

APACHE, Acute Physiology and Chronic Health Evaluation; ICU, intensive care unit; LOS, length of stay; MPM, Mortality Probability Model; SD, standard deviation. *P-value between patients aged $50-64.9$ and those $65-79.9$ years.

**P-value between patients aged $50-64.9$ and those $>80$ years.

***P-value between patients aged $65-79.9$ and those $\geq 80$ years.

\# Patients discharged alive $<28$ days after hospital admission were considered to be survivors.

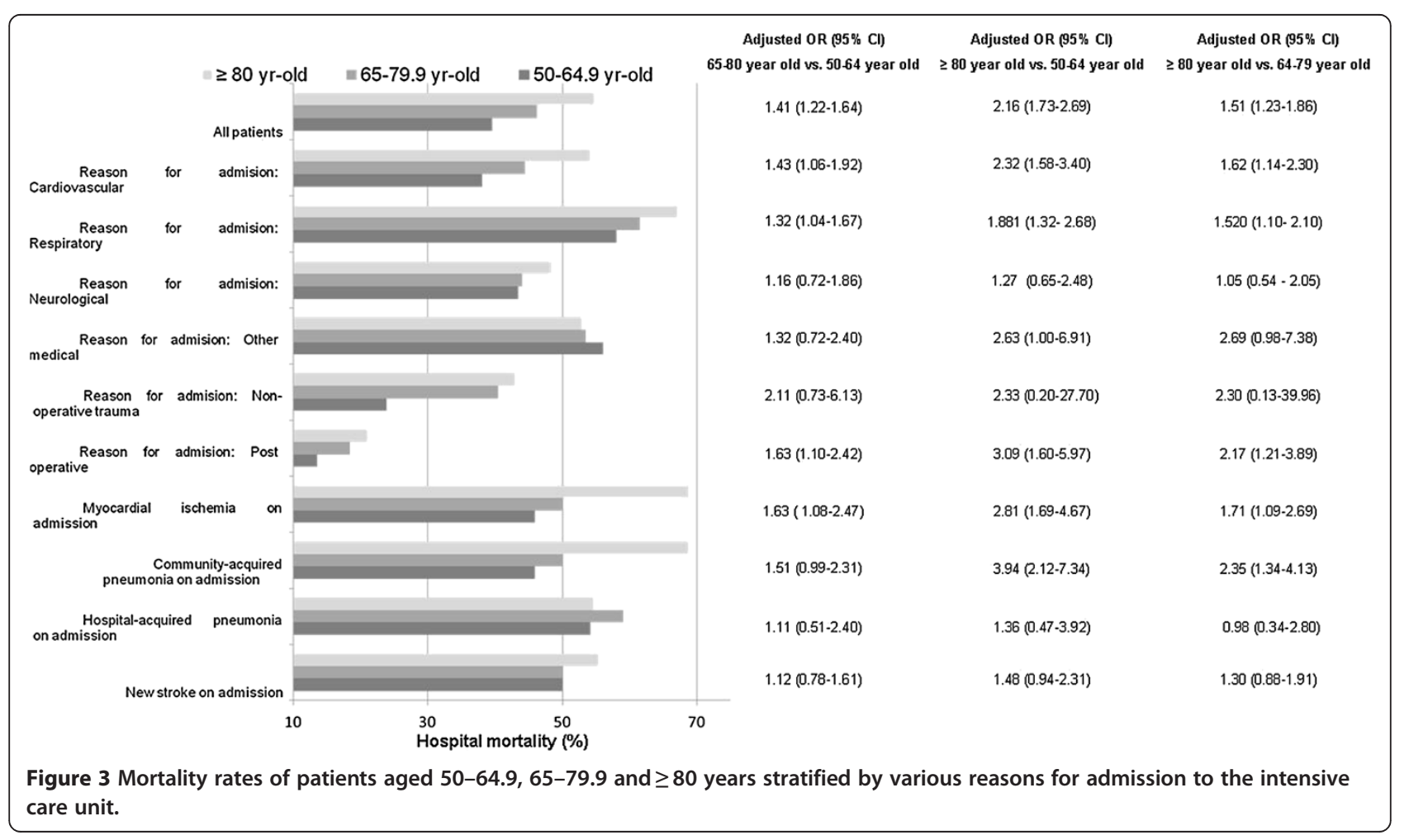


study that classified patients into 75-79, 80-84 and $\geq$ 85 year age groups found that age was not associated with ICU mortality, but with long-term mortality (aOR: 2.17, for patients $\geq 85$ years old and 1.82 , for patients $80-84$ years old) [6]. Another study found that patients aged $75-84$ and $\geq 85$ year-old had aORs of 1.38 (95\% CI, $1.19-1.59)$ and 1.53 (95\% CI, 1.29-1.81), respectively for 28-day mortality as compared with the 65-74 year-age group [7]. A secondary analysis of data from a randomized trial comparing the effects of dopamine and norepinephrine in patients with shock found that the mortality rates were higher in the old (75-84 years) and very old ( $\geq 85$ years) patients at 28 days, at hospital discharge, and after 6 and 12 months [21]. Most very old patients were dead at 6 (92\%) and 12 months (97\%) with mortality rates increasing with age in all types of shock [21]. A retrospective Norwegian cohort study $(n=27,921)$ found that the hospital mortality was $21.4 \%$ in patients aged $50-79.9$ years and $32.4 \%$ in patients aged $>80$ years, who also received less mechanical ventilation (40.6\% versus $56.1 \%$ ) and had shorter median ventilatory support time ( 0.8 days versus 1.9 days) [22]. The mortality of the very elderly patients may be affected by admission type. A retrospective cohort study that the 30-day mortality of elderly patients ( $\geq 80$ years) was $43.7 \%$ in medical, $39.6 \%$ in acute surgical, and $11.6 \%$ in elective surgical ICU patients with a corresponding adjusted 30-day mortality rate ratios compared with the 50-64 year-old patients were 2.7 (95\% CI, 2.5-3.0) in medical, 2.7 (95\% CI, 2.4-3.0) in acute surgical and 5.2 (95\% CI, 4.1-6.6) in elective surgical ICU patients [17]. The adjusted mortality rate ratios for 31-365-day mortality among elderly patients were 2.5 (95\% CI, 2.1-2.9) for medical, 2.2 (95\% CI 1.9-2.5) for acute surgical and 1.9 (95\% CI, 1.6-2.3) for elective surgical ICU patients [17]. A study that used Project IMPACT data for 124,885 patients treated from 2001 to 2004 found that mortality rates approximately doubled in the elective surgical group among patients aged in their $70 \mathrm{~s}(2.4 \%), 80 \mathrm{~s}(4.3 \%)$, and $90 \mathrm{~s}(9.2 \%)$ but rose less dramatically in the medical group $(27.0 \%, 30.7 \%$, and $36.0 \%$, respectively) [8]. Old age (> 65 years) has been associated with increased community-acquired pneumonia mortality [23] and ARDS mortality (OR per additional 10 year, $1.27 ; 95 \%$ CI, 1.07-1.50) [24]. In the current study, the ICU mortality was similar in the three age groups, but the hospital mortality was significantly higher in patients aged $\geq 80$ years having a higher adjusted mortality risk compared to younger age groups (50-64.9 and 6579.9 years). This was observed in different admission types, except for admissions due to neurologic disease and hospital-acquired pneumonia. This could be because patients aged $\geq 80$ years had high prevalence of chronic illnesses and functional disability in our study.

The findings of this study should be interpreted in the light of its strengths and limitations. Strengths include the large sample size. Limitations include being a monocenter study and lack of data on post-ICU care processes, which may have affected hospital outcome, and on longterm outcomes such as cognitive function and disability. Critical illness in old people has been associated with decline in cognitive function. Analysis of data from a prospective cohort study of 2929 individuals $\geq 65$ year-old without dementia showed that adjusted hazard ratio for incident dementia was 1.4 following a noncritical illness hospitalization (95\% CI, 1.1-1.7; $\mathrm{p}=0.001$ ) and 2.3 following a critical illness hospitalization (95\% CI, 0.9-5.7; $\mathrm{p}=0.09$ ) [25]. This may be one of the reasons for increased mortality after ICU discharge.

\section{Conclusions}

In conclusion, we have found that patients aged $\geq 80$ years accounted for a significant proportion of patients admitted to a tertiary-care ICU in Saudi Arabia. However, their proportion was lower than those of developed countries likely due to the younger Saudi population. The treating intensivists supported them with life sustaining interventions, such as mechanical ventilation and renal replacement therapy, similar to younger groups, but the Do-NotResuscitate practice was more common in them. More than half of them died in the hospital with age $\geq 80$ years being an independent risk factor for hospital mortality.

\section{Key messages}

- Patients aged $\geq 80$ years represented a significant portion of ICU admissions (7.9\% of all admissions and $12.8 \%$ of patients aged $\geq 50$ years).

- They received life support measures such as mechanical ventilation and renal replacement therapy similar to younger patients. However, they had higher frequency of Do-Not-Resuscitate orders.

- Patients aged $>80$ years had higher hospital mortality than the younger patients mostly after ICU discharge.

- Age $\geq 80$ years was associated with almost 2 times increase in the adjusted hospital mortality risk compared with age 50-64.9 years.

\section{Abbreviations}

APACHE: Acute Physiology and Chronic Health Evaluation; Cl: Confidence interval; ICU: Intensive care unit; INR: International Normalized Ratio; MPM: Mortality Probability Model; OR: Odds ratio.

\section{Competing interests}

The authors declare that they have no competing interests.

\section{Authors' contributions}

HMD: Conception and design, analysis and interpretation of data, drafting of the manuscript, critical revision of the manuscript for important intellectual content, approved the final version to be published. HMT: Statistical analysis and interpretation of data, critical revision of the manuscript for important intellectual content, approved the final version to be published. SM: Data collection, interpretation of data, critical revision of the manuscript for 
important intellectual content, approved the final version to be published. MRS: Data collection, interpretation of data, critical revision of the manuscript for important intellectual content, approved the final version to be published. YMA: Conception and design, analysis and interpretation of data, drafting of the manuscript, critical revision of the manuscript for important intellectual content, approved the final version to be published. All authors read and approved the final manuscript.

\section{Author details}

${ }^{1}$ College of Medicine, King Saud bin Abdulaziz University for Health Sciences and Intensive Care Department, King Abdulaziz Medical City, Riyadh 11426, Kingdom of Saudi Arabia. ${ }^{2}$ King Abdullah International Medical Research Center, Riyadh 11426, Kingdom of Saudi Arabia. ${ }^{3}$ Department of Internal Medicine, American University of Beirut-Medical Center, Beirut, Lebanon. ${ }^{4}$ Intensive Care Department, King Abdulaziz Medical City, Riyadh 11426 , Kingdom of Saudi Arabia. ${ }^{5}$ Intensive Care Department, King Abdulaziz Medical City, Riyadh, Saudi Arabia. ${ }^{6}$ College of Medicine, King Saud bin Abdulaziz University for Health Sciences, PO Box 22490, Mail code 1425 , Riyadh 11426, Kingdom of Saudi Arabia.

Received: 4 September 2014 Accepted: 10 December 2014 Published: 20 December 2014

\section{References}

1. Angus DC, Linde-Zwirble WT, Lidicker J, Clermont G, Carcillo J, Pinsky MR: Epidemiology of severe sepsis in the United States: analysis of incidence, outcome, and associated costs of care. Crit Care Med 2001, 29(7):1303-1310.

2. Ewig S, Birkner N, Strauss R, Schaefer E, Pauletzki J, Bischoff H, Schraeder P, Welte T, Hoeffken G: New perspectives on community-acquired pneumonia in 388406 patients. Results from a nationwide mandatory performance measurement programme in healthcare quality. Thorax 2009, 64(12):1062-1069.

3. Sparkes DJ, Smith GB, Prytherch D: Intensive care requirements for an ageing population-a microcosm of problems facing the NHS? Clin Med 2004, 4(3):263-266.

4. Sinuff T, Kahnamoui K, Cook DJ, Luce JM, Levy MM: Rationing critical care beds: a systematic review. Crit Care Med 2004, 32(7):1588-1597.

5. Boumendil A, Angus DC, Guitonneau AL, Menn AM, Ginsburg C, Takun K, Davido A, Masmoudi R, Doumenc B, Pateron D, Garrouste-Orgeas M, Somme D, Simon T, Aegerter P, Guidet B, ICE-CUB study group: Variability of intensive care admission decisions for the very elderly. PLoS One 2012, 7(4):e34387.

6. Somme D, Maillet JM, Gisselbrecht M, Novara A, Ract C, Fagon JY: Critically ill old and the oldest-old patients in intensive care: short- and long-term outcomes. Intensive Care Med 2003, 29(12):2137-2143.

7. Fuchs L, Chronaki CE, Park S, Novack V, Baumfeld Y, Scott D, McLennan S, Talmor D, Celi L: ICU admission characteristics and mortality rates among elderly and very elderly patients. Intensive Care Med 2012, 38(10):1654-1661.

8. Nathanson BH, Higgins TL, Brennan MJ, Kramer AA, Stark M, Teres D: Do elderly patients fare well in the ICU? Chest 2011, 139(4):825-831.

9. Boumendil A, Somme D, Garrouste-Orgeas M, Guidet B: Should elderly patients be admitted to the intensive care unit? Intensive Care Med 2007, 33(7):1252-1262

10. Arabi Y, Alshimemeri A, Taher S: Weekend and weeknight admissions have the same outcome of weekday admissions to an intensive care unit with onsite intensivist coverage. Crit Care Med 2006, 34(3):605-611.

11. Sulter G, Steen C, De Keyser J: Use of the Barthel index and modified Rankin scale in acute stroke trials. Stroke 1999, 30(8):1538-1541.

12. Knaus WA, Draper EA, Wagner DP, Zimmerman JE: APACHE II: a severity of disease classification system. Crit Care Med 1985, 13(10):818-829.

13. Lemeshow S, Teres D, Klar J, Avrunin JS, Gehlbach SH, Rapoport J: Mortality Probability Models (MPM II) based on an international cohort of intensive care unit patients. JAMA 1993, 270(20):2478-2486.

14. Goldhill DR, Sumner A: Outcome of intensive care patients in a group of British intensive care units. Crit Care Med 1998, 26(8):1337-1345.

15. Lutz W, Sanderson W, Scherbov S: The coming acceleration of global population ageing. Nature 2008, 451(7179):716-719.

16. Bagshaw SM, Webb SA, Delaney A, George C, Pilcher D, Hart GK, Bellomo R: Very old patients admitted to intensive care in Australia and New Zealand: a multi-centre cohort analysis. Crit Care 2009, 13(2):R45.
17. Nielsson MS, Christiansen CF, Johansen MB, Rasmussen BS, Tonnesen E, Norgaard M: Mortality in elderly ICU patients: a cohort study. Acta Anaesthesiol Scand 2014, 58(1):19-26.

18. United Nations, Department of Economic and Social Affairs, Population Division: World Population Prospects: The 2010 Revision, Volume I: Comprehensive Tables. ST/ESA/SER.AV313. In. 2011.

19. Garrouste-Orgeas M, Tabah A, Vesin A, Philippart F, Kpodji A, Bruel C, Gregoire C, Max A, Timsit JF, Misset B: The ETHICA study (part II): simulation study of determinants and variability of ICU physician decisions in patients aged 80 or over. Intensive Care Med 2013, 39(9):1574-1583.

20. Wunsch H, Linde-Zwirble WT, Harrison DA, Barnato AE, Rowan KM, Angus DC: Use of intensive care services during terminal hospitalizations in England and the United States. Am J Respir Crit Care Med 2009, 180(9):875-880.

21. Biston P, Aldecoa C, Devriendt J, Madl C, Chochrad D, Vincent JL, De Backer D: Outcome of elderly patients with circulatory failure. Intensive Care Med 2014, 40(1):50-56.

22. Andersen $\mathrm{FH}$, Kvale R: Do elderly intensive care unit patients receive less intensive care treatment and have higher mortality? Acta Anaesthesiol Scand 2012, 56(10):1298-1305.

23. Mandell LA, Wunderink RG, Anzueto A, Bartlett JG, Campbell GD, Dean NC, Dowell SF, File TM Jr, Musher DM, Niederman MS, Torres A, Whitney CG, Infectious Diseases Society of America; American Thoracic Society: Infectious diseases society of America/American thoracic society consensus guidelines on the management of community-acquired pneumonia in adults. Clin Infect Dis 2007, 44(Suppl 2):S27-S72.

24. Phua J, Badia JR, Adhikari NK, Friedrich JO, Fowler RA, Singh JM, Scales DC, Stather DR, Li A, Jones A, Gattas DJ, Hallett D, Tomlinson G, Stewart TE, Ferguson ND: Has mortality from acute respiratory distress syndrome decreased over time?: A systematic review. Am J Respir Crit Care Med 2009, 179(3):220-227.

25. Ehlenbach WJ, Hough CL, Crane PK, Haneuse SJ, Carson SS, Curtis JR, Larson EB: Association between acute care and critical illness hospitalization and cognitive function in older adults. JAMA: J Am Med Assoc 2010, 303(8):763-770.

doi:10.1186/1471-2253-14-126

Cite this article as: Al-Dorzi et al:: Characteristics, management and outcomes of critically ill patients who are 80 years and older: a retrospective comparative cohort study. BMC Anesthesiology 2014 14:126.

\section{Submit your next manuscript to BioMed Central and take full advantage of:}

- Convenient online submission

- Thorough peer review

- No space constraints or color figure charges

- Immediate publication on acceptance

- Inclusion in PubMed, CAS, Scopus and Google Scholar

- Research which is freely available for redistribution 